\title{
Research on the Application of GIS Technology in Spatial Mode Customer Relationship Management System
}

\author{
Zheng Hongjian, Xue Fei, Wang Chunxiu \\ Hubei Academy of Scientific and Technical Information, Wuhan, P.R.China, 430072
}

(E-mail: fire007sha@163.com)

\begin{abstract}
This paper applies spatial analysis and GIS coupling to represent spatial visualization of the customer's information and brings forward the application of GIS technology in spatial type customer relationship management. This paper believes that through spatial customer relationship management, the enterprise can automatically accumulate assorted information including the spatial one of the customer in previous business to form the spatial database of the customer relationship. The conclusion is that the analysis and process function of the spatial database system of customer relationship will help better the comprehension of the customer's needs so as to make valid prediction of the customer and the development potential.
\end{abstract}

Key words: GIS; CRM; Management; Spatial mode

\section{Introduction}

Spatial mode customer relationship management is to use GIS technology to dig out the relevant information concerning the space location and space distribution in the customer relationship, to make space visible express about the customers' information, and to use spatial analytic means to help the enterprise to better the management of customers, to attract potential customers and to retain valued customers. Through spatial mode customer relationship management, the enterprise can automatically accumulate various kinds of customer information including space information in the business activities so as to form the customer relationship spatial data base. A sound customer data base can not only to help the enterprise to retain the current customers but also enable the enterprise to retrieve the customers lost. The analytic and processing function of the customer relationship spatial data base assists the enterprise to do all-around analysis and management of customers, to better understand the customers' needs, to provide service for customers nearby and to efficiently predict the development potential of the customer.

\section{Research Status at Home and Abroad}

In the current CRM market, the manufacturers are in the preliminary stage of the competition, and yet none enterprise has claimed to be able to offer comprehensive customer relationship management solutions directed at customers of all industries. The function modes of the mainstream CRM products are customer call center with telephone as the main channel, sales force automation component products, data mining software and network interactive software. Systematic research and implementation on the customer relationship management from the angle of space and aimed at the distribution feature of the customers of the logistics enterprises is very rare. ESRI, MapInfo, Oracle from abroad present the solutions for the application of CIS in CRM. Inside the country, SuperMap Software Co., Ltd has developed customer relationship management system for the management of marketing, sales and technology support of its self-developed series of SuperMap software. But in general, to apply GIS technology in analysis of customers' spatial distribution and market decisions, and to make the spatial management of customer relationships are not commonly known by CRM providers; the products are few with incomplete functions and the promotion is limited; the business application of GIS in the customer management of logistic enterprises is even rarer. Thus the application of GIS in the industry is ponderable for research on the specific implementation of customer relationship management in the industry. 


\section{GIS and Spatial Customer Relationship Management}

The different functions of various information systems are all based on the abundant data in the data base. Which makes the geographic information system different from common information management system is that with the support of GIS, the information provided to the user is not just simple words and figures (which are called attribute information), but also spatial vectorgraph or raster images process by GIS, i.e. what we called spatial information data. The spatial information is that the information itself contains the shape, distribution, space orientation, connections in space, etc., just like geographic entities such as a road, a bridge, a building, a prefecture, etc. geographic information system, as a kind of advanced computer technologies, can combine the graphic data management system with attribute data management system. In digital computers, all information is represented by numbers; also, GIS is the information processor on the basis of digital computation, it describes the objective world and the geographic entity inside through numbers. In general, the functions of GIS in the customer relationship management are as follows:

\subsection{Customer space orientation management}

The customer space orientation management is to excavate the information relevant to space location and space distribution in the customer relationship, to make visible express of the spatial information and to assist the enterprise with spatial analytic methods to better management customers, attract potential customers and to retain the most valued customers, such as to refer to the customer distribution, whether the space distribution of the marketing plan is reasonable, how to make promotion plan according to the customer density and distribution, what is the spatial distribution regularities of customer complaint, where is the major location of the valued customer, what is competitors' situations in the designated areas and so forth. As one useful helper for geographic analysis, GIS plays a significant role in the assistant of management and analysis of the customer relationship and of the mastery of the complicated supply and demand relations in the market for the enterprises from the view of regional space.

Through spatial mode customer relationship management, the enterprise can automatically accumulate various kinds of customer information including space information in the business activities so as to form the customer relationship spatial data base. The analytic and processing function of the customer relationship spatial data base assists the enterprise to do all-around analysis and management of customers, to better understand the customers' needs, to provide service for customers nearby and to efficiently predict the development potential of the customer.

\subsection{Spatial analysis of customer}

The influence of the demand features of different customers on the economic activity is totally different. In different area, the primary demand level is sometimes different due to different consumption custom and other factors. For example, the best-selling product in the market of an area might be only in the second place in that of B area. In the mean time, the change in consumption level, consumption construction and consumption behaviour caused by the economic change can also result in the change in consumption regional space structure and distribution. As the city expands, the population suburbanization will certainly stimulate the business development in the suburbs which will make the customer distribution far away from the city center and scattered.

When launching products, the enterprise has two strategies: product standardization and differentiation strategy. Product standardization strategy refers to that instead of considering different areas, the enterprise launches the same product for the whole market; it directs at the sameness in the customer's demands. Product differentiation strategy refers to that the enterprise designs different products or alter the product according to different consumption demands in different areas.

\subsection{Customer regional division according to the customer's location}

The market features differ in different regions and the sale needs different marketing

Journal on Innovation and Sustainability, São Paulo, vol.02, n.02, p.34 - 37, 2011 
plan according to markets in different regions. In general, the marketing plan chosen should have two features: one is that it can be easily accepted by the target customers and two, it has great profit potential. The marketing plan chosen should be on the full knowledge of customers' demand in target area; that is because the extent of the marketing plan is to seek for the complete coverage of the demand in the target market. It requires the enterprise to master the demand status and purchase motivation of the customer to various products, or otherwise the business risks born by the enterprise will increase and it will be difficult to achieve the enterprise operation goal. And the depth of the marketing plan is to occupy more market shares; the enterprise needs to mater the demand degree and purchase capability of the customer on goods so as to attract more customers and improve customer satisfaction degree.

\section{Technology for Realization of Spatial Mode Customer Relationship Management}

According to the above analysis of the function of GIS in customer relationship management, spatial customer management means spatial analysis technology is needed. In different development stage and technology conditions, the coupling levels of GIs and spatial analysis are different. The coupling of GIS and spatial analysis can be classified in three different modes:

\subsection{Loose-coupling of spatial analysis and GIS}

There is no direct link in language between GIS and this mode of spatial analysis whose run is independent. To add data transformation interface between GIS and spatial analysis software, the data needed for spatial analysis will be acquired from GIS data base and the output of the analysis can be stored in the GIS data base; the spatial query and display is completed by GIS. The kind of development mode cost less with small risk and is easy to realize. And it will maintain the original professional feature of spatial analysis. However, the systematic efficiency of this mode is low which increases the difficulty for the non-experts to get familiar with it and to use it. The general mode construction is as follows:

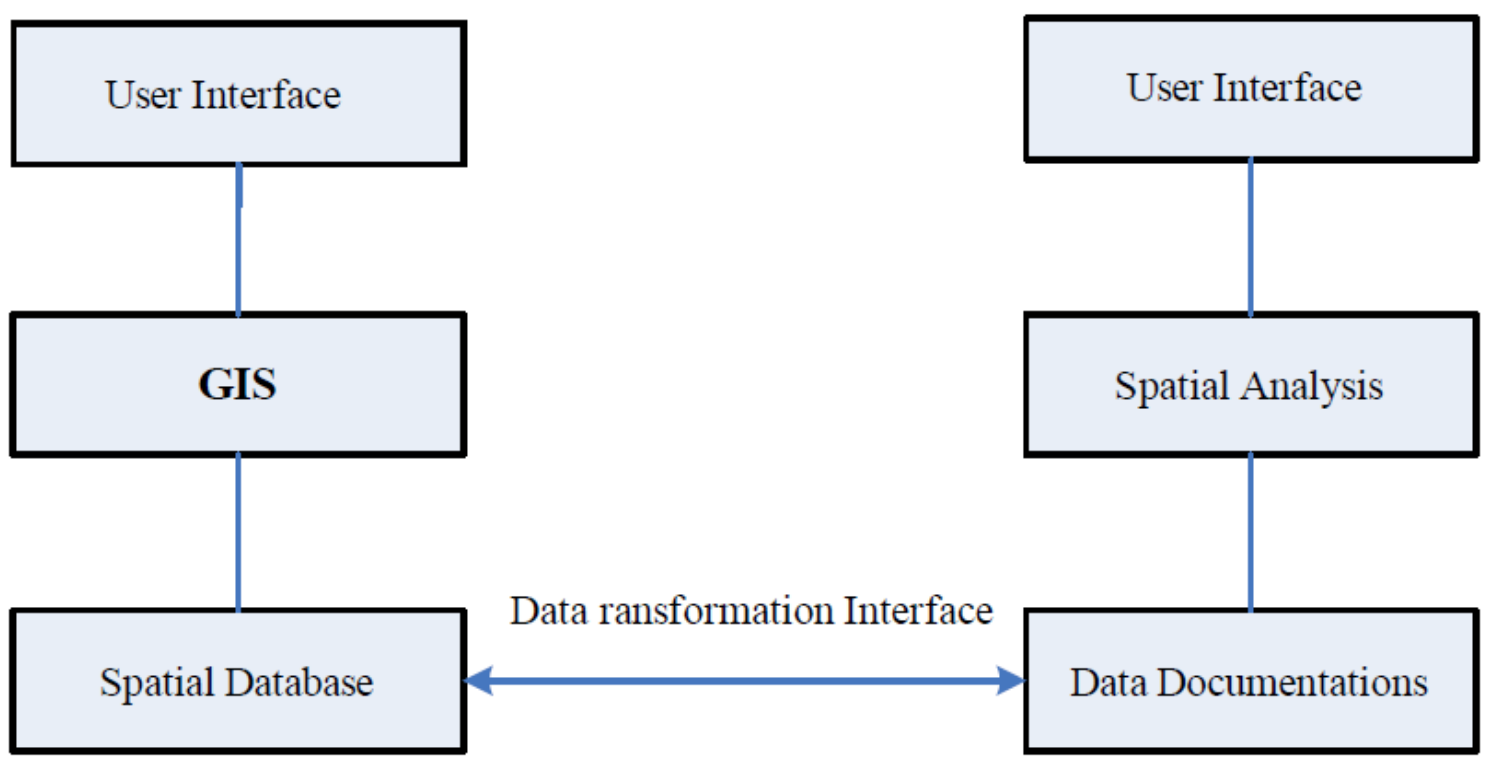

Figure 1 - Loose-coupling of Spatial Analysis and GIS

\subsection{Tight coupling of spatial analysis and GIS}

In this mode, one system predominates with the function of another system added in. the two has the same user interface and seamless connection is realized via shared documentation and storage. There are two ways for this connection: one is to add the spatial analysis mode into GIS; the other is to extend the function of the spatial analysis mode with GIS function. Through this mode, GIS can not only provide graphic demonstration for spatial analysis but also use the relevant information in GIS for the spatial analysis computation. The general mode is as shown in illustration 2. 


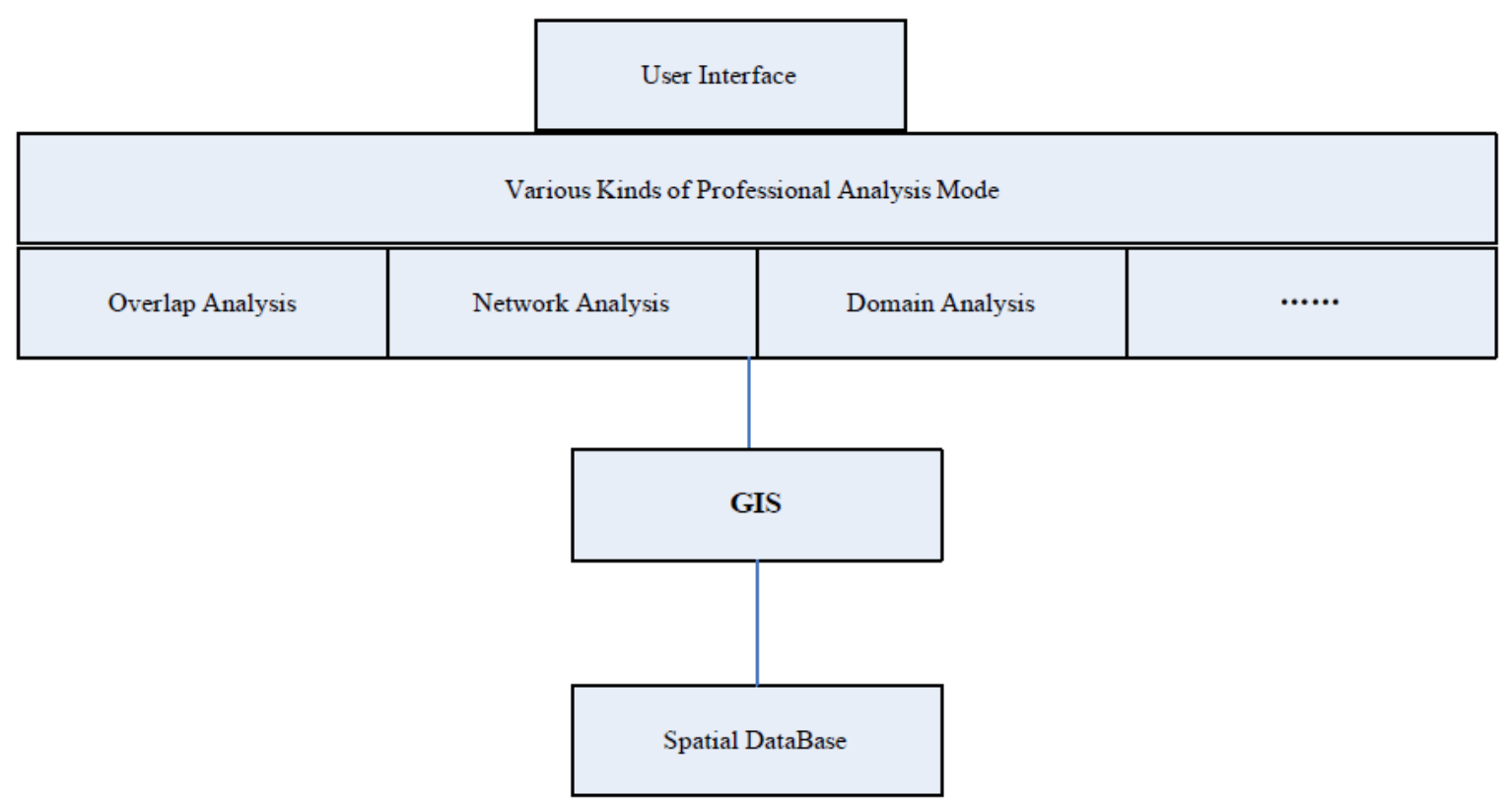

Figure 2 - Tight Coupling of Spatial Analysis and GIS

\subsection{Spatial analysis and GIS}

In this mode, the theoretical research and practical application of some professional application mode is becoming mature and the mode is widely accepted as the spatial analysis tool. With the development and perfection of GIS base platform, the mode can be brought into the GIS base platform which will therefore be the basic spatial analysis tool so as to realize complete integration. This is the supreme coupling.

\section{Conclusions}

The research in this paper uses the tight coupling of spatial analysis and GIS mode. Currently, with the development of software technology, GIS application can be embedded directly into the CRM system to realize the seamless integration of GIS application and CRM; the application of relational data for the storage and management of spatial data enables GIS data and CRM data to be stored and managed together. These factors make the application of GIS technology in CRM possible. GIS, as a technology for spatial information input, process, storage, management, analysis and output, the key of the application lies in the visible analysis of spatial phenomenon, process and rules. The application of GIS in CRM is actually a specific application of business geographic analysis.

\section{References}

[1] Liang Jun, Liu Baoquan. CRM Development and Application Based on GIS [C] Papers of China GIS Annual Meeting (In Chinese)

[2] Xian Shengchang. GIS Components Design and Realization Based on COM Technology [D] Degree Papers of Master Candidate. Daqing: Daqing Petroleum Institute, 2005:7-9 (In Chinese)

[3] Ronald H.Ballou.Heuristic. Rules of Thumb for Logistics Decisions [J].Journal of Business Logistics, 1989, 15-16

[4] Jill McCoy, Kevin Johnston. Using ArcGIS Spatial Analyst [J].GIS by ESRITM, 2001, 7(3):105-342

[5] Mohamed, M Plante.R.Remote Sensing and Geographic Information Systems for Developing Countries [J].Geoscience and Remote Sensing Symposium, 2002,4 (1):2285-2287 